\title{
Spastic Diplegia
}

National Cancer Institute

\section{Source}

National Cancer Institute. Spastic Diplegia. NCI Thesaurus. Code C34781.

A type of cerebral palsy characterized by spasticity and hypertonia of the lower extremities bilaterally, particularly the legs, hips, and pelvis; this is the most common (70\%) form of cerebral palsy. 